\title{
PARAMETRIC STUDIES ON THE COMPONENT-BASED APPROACH TO MODELLING BEAM BOTTOM FLANGE BUCKLING AT ELEVATED TEMPERATURES
}

\author{
Guan Quan*, Shan-Shan Huang, Ian Burgess
}

\author{
University of Sheffield, Department of Civil and Structural Engineering, Sheffield, UK \\ * corresponding author: g.quan@sheffield.ac.uk
}

\begin{abstract}
In this study, an analytical model of the combination of beam-web shear buckling and bottom-flange buckling at elevated temperatures has been introduced. This analytical model is able to track the force-deflection path during post-buckling. A range of 3D finite element models has been created using the ABAQUS software. Comparisons have been carried out between the proposed analytical model, finite element modelling and an existing theoretical model by Dharma (2007). Comparisons indicate that the proposed method is able to provide accurate predictions for Class 1 and Class 2 beams, and performs better than the existing Dharma model, especially for beams with high flange-to-web thickness ratios. A component-based model has been created on the basis of the analytical model, and will in due course be implemented in the software Vulcan for global structural fire analysis.
\end{abstract}

KEYWORDS: shear buckling; bottom-flange buckling; component-based model; fire.

\section{INTRODUCTION}

The structural behaviour of a real composite frame observed in the full-scale Cardington Fire Tests in 1995-96 [1, 2] was very different from that observed from furnace tests on isolated composite beams. This stimulated a general awareness of the importance of performance-based design, which sufficiently considers the interactions between different members in the structure. Wald et al. [3] reported on the results of a collaborative research project, including tensile membrane action and robustness of structural steel joints under natural fire, to investigate the global structural behaviour of a compartment on the 8-storey steel-concrete composite frame building at the Cardington laboratory during a BRE large-scale fire test. This report further revealed the structural integrity of structures under fire conditions. However, full-scale fire tests are expensive. To carry out finite-element modelling of an entire structure, including its joints, using solid elements is computationally demanding. The Component Method provides a practical alternative approach to modelling the joints and their adjacent zones; component-based joint models can be included in global structural analysis using much lower numbers of beam-column and shell elements.

The Cardington fire tests [4] indicated that beamweb shear buckling, as well as beam bottom-flange buckling, near to the ends of steel beams, is very prevalent under fire conditions, as shown in Fig. 1

These phenomena can have significant effects on the beam deflection, as well as the force distribution within the adjacent joint. As joints are one of the most vulnerable element in steel structures, due to their complex behaviours [5], it is significant to fully

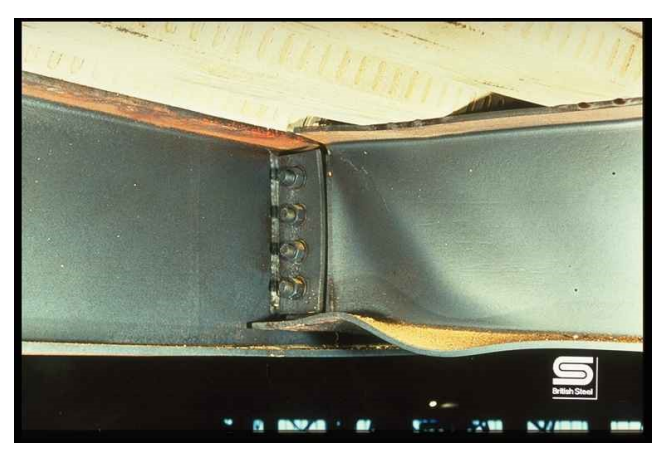

Figure 1. Shear buckling and bottom-flange buckling in Cardington fire test 4].

consider the effects of the buckling elements in the vicinity of beam-column joints in fire. Research by Elghazouli [6] addressed the influence of local buckling on frame response, although local buckling may have an insignificant influence on the fire resistance of isolated members. However, the local buckling model presented in Elghazouli's work is based on elastic plate buckling theory [7], which is not appropriate for representing the buckling behaviour of Class 1 and 2 sections.

In this study, the principles of the analytical model [8], which combines the beam-web shear buckling and bottom-flange buckling at elevated temperatures, are briefly reviewed. This model is capable of predicting local buckling behaviour in the post-buckling stage. Together with the assumption that the characteristics of the buckling zone are identical to those of the normal beam in the pre-buckling stage, the analytical model is able to track the complete force-deflection path of the end-zone of the beam, from initial loading 


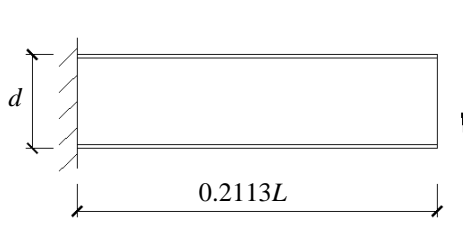

(a) Beam up to the Point of

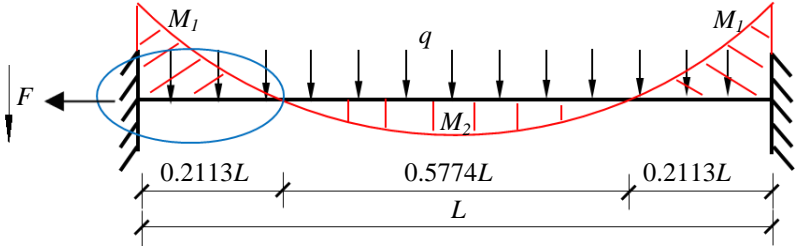

(b) Bending moment diagram

Figure 2. The analytical model.

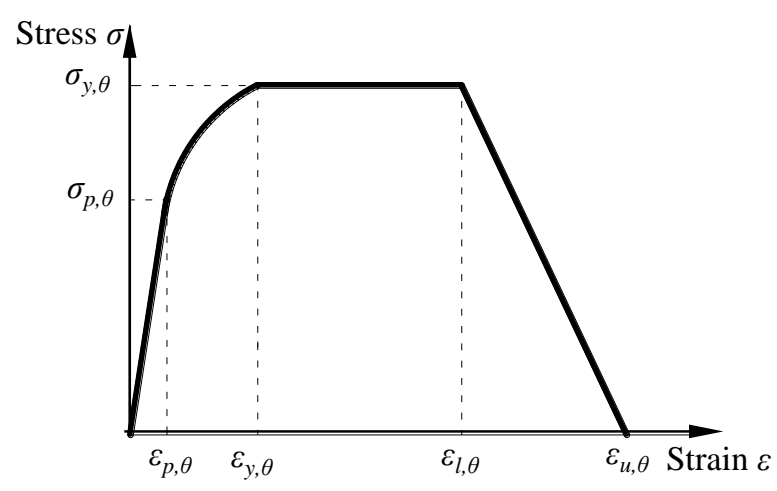

FiguRE 3. Stress-strain relationship of structural steel.

to post-buckling. The analytical model has for the first time been validated in uniformly distributed loading condition. A range of $3 \mathrm{D}$ finite element models has been created using ABAQUS, and comparisons have been carried out between these, the proposed analytical model, and Dharma's model [9], which indicate that the proposed method gives better predictions overall than Dharma's model. A component-based model has been created on the basis of the analytical model, and will be implemented into the software Vulcan for global structural fire analysis.

\section{Development of analytical MODEL}

The development of the analytical model is explained using a short cantilever I-beam section (Fig. 2) as an example. By changing the cantilever length and by applying different combinations of uniformly distributed load and shear force at the beam-end, the cantilever is able to represent part of a fixed-ended beam from its end to the point of contraflexure under a uniformly distributed load. It can be calculated that the distance from one end of the beam to its adjacent contraflexure point is equal to 0.2113 of the whole beam length.

When the bottom-flange buckling wavelength calculated from Eqns. (1) and (2) is shorter than the beam depth, the length of the buckling zone is taken as identical to the $L_{p}$ calculated from these equations. Otherwise, the length of the buckling zone is capped

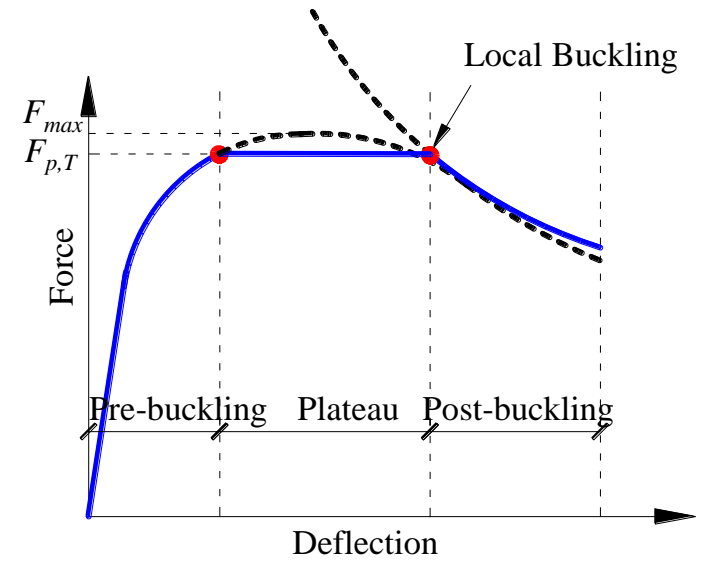

FIGURE 4. Schematic force-deflection of a buckling panel.

to the beam depth $d$ :

$$
\begin{gathered}
\beta=0.713 \sqrt{\frac{275}{f_{y}}}\left(\frac{d}{b}\right)^{1 / 4}\left(\frac{t_{f}}{t_{w}}\right)^{3 / 4}\left(\frac{k_{E} / k_{y}}{0.7}\right), \\
L_{p}=2 \beta c,
\end{gathered}
$$

where $c$ is the outstand of the flange. If the material properties, shown in Fig. 3, for steel at temperatures higher than $400^{\circ} \mathrm{C}$, are used, the vertical force-deflection relationship of the buckling panel can be illustrated qualitatively as in Fig. 4. The proposed analytical model divides the loading procedure into three stages: pre-buckling, plateau and post-buckling.

In the pre-buckling stage, the calculation rules follow those for beams at elevated temperatures. The plateau $\mathrm{AB}$ occurs when the sectional plastic moment capacity is reached at the middle of the buckling zone. The Point B is the point at which bottom-flange buckling occurs. The plastic buckling mechanism is shown in Fig. 5 in the post-buckling stage it is assumed that the collapse mechanism is composed of a combination of yield lines and plastic yield zones. The calculation principle is based on equality of the internal plastic work and the loss of potential energy of the external load. The internal plastic work $W_{i n t}$ includes the work done in the flanges, which is composed $\sum_{i}\left(W_{l}\right)_{i}$ of due to rotation about yield lines and $\sum_{j}\left(W_{z}\right)_{j}$ due to axial deformation of the plastic zones, as well as the work $W_{w}$ done by the beam web due to its deforma- 


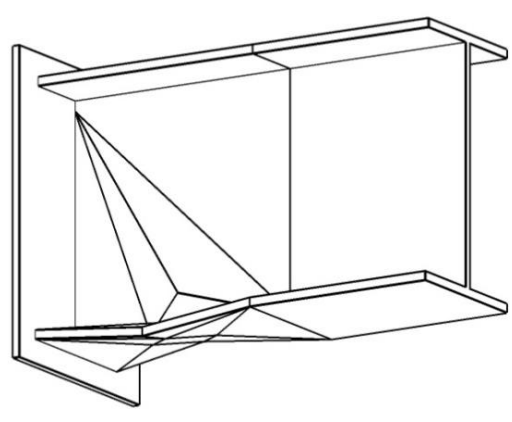

Figure 5. Plastic Buckling Mechanism.

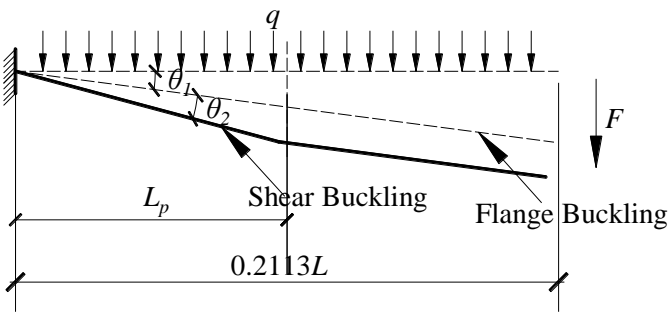

FIGURE 6 . The effects of flange buckling and beamweb shear buckling on beam vertical deflection.
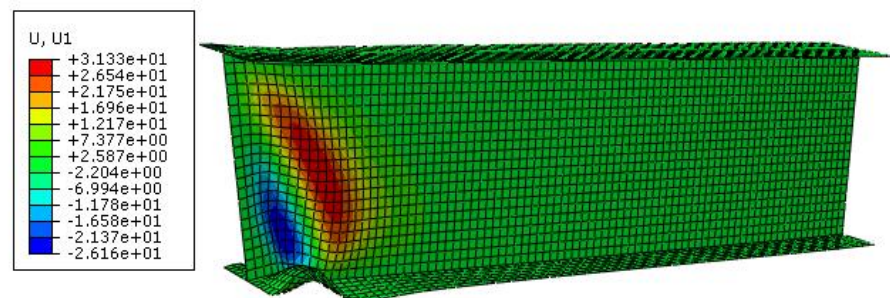

(a)

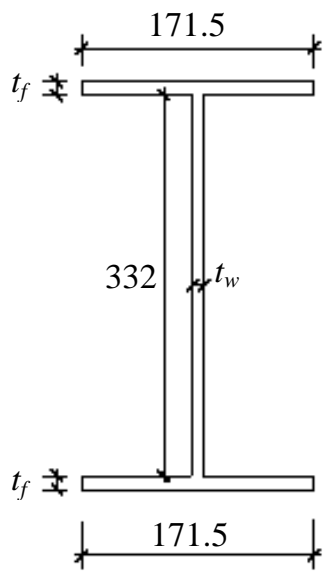

(b)

FIGURE 7. Finite element model: (a) image of finite element model; (b) cross-section dimension.

tion during shear buckling. The total internal work can be expressed as

$$
W_{i n t}=\frac{1}{4} \sum_{i}\left(l_{p} t^{2} f_{y} \Theta_{1}\right)_{i}+\sum_{j}\left(A_{p} t f_{y} \varepsilon\right)_{j}+W_{w}
$$

The total deflection of the buckling zone is composed of the deflection caused by simultaneous bottomflange buckling and beam-web shear buckling, as shown in Fig. 6. The influence of bottom-flange buckling is to cause a rotation of the whole beam-end about the top corner of the beam, while the effect of shear buckling is a parallel movement of the opposite edges of the shear panel. When applying uniformly distributed load on top of the beam, as well as a shear force at the beam-end, the total external work can be expressed as:

$$
\begin{aligned}
W_{\text {ext }}= & \sum_{i} P_{i} \Delta_{i}=0.5 \times(0.2113 L)^{2} q \Theta_{1} \\
& +(0.2113 L) \times F \Theta_{1}+0.5 L_{p}^{2} q \Theta_{2} \\
& \quad+q\left(0.2113 L-L_{p}\right) \times L_{p} \Theta_{2}+F L_{p} \Theta_{2} .
\end{aligned}
$$

The theoretical model can be applied to different load and boundary conditions.

\section{VAlidation against Finite ELEMENT MODELling}

\subsection{Development of the ABAquS MODELS}

The commercial finite element software ABAQUS was used to simulate the buckling phenomena in the vicinity of beam-column connections at $615^{\circ} \mathrm{C}$. The fournoded shell element S4R [10], which is capable of simulating buckling behaviour, was adopted. A $15 \mathrm{~mm}$ $\times 15 \mathrm{~mm}$ element size was used, after a mesh sensitivity analysis. The Riks approach was used in order to identify the descending curve at the post-buckling stage. Cantilever models with the same loading and boundary conditions as the analytical model were set up. An image of the ABAQUS model is shown in Fig. 7(a). The cross-section dimensions are shown in Fig. 7 (b). All the cantilevers shared the same configuration except for the beam web and flange thicknesses. The beam cross-section dimensions were based on the universal beam UB356x171x51, whose beam web and flange thicknesses are $7.4 \mathrm{~mm}$ and $11.5 \mathrm{~mm}$ respectively. As the analytical model applies generally to Class 1 and 2 beams, the thicknesses of the beam webs and flanges vary within this range. Therefore, the thicknesses of the beam webs were varied from $5.5 \mathrm{~mm}$ to $8 \mathrm{~mm}$, while those of the beam flanges were 

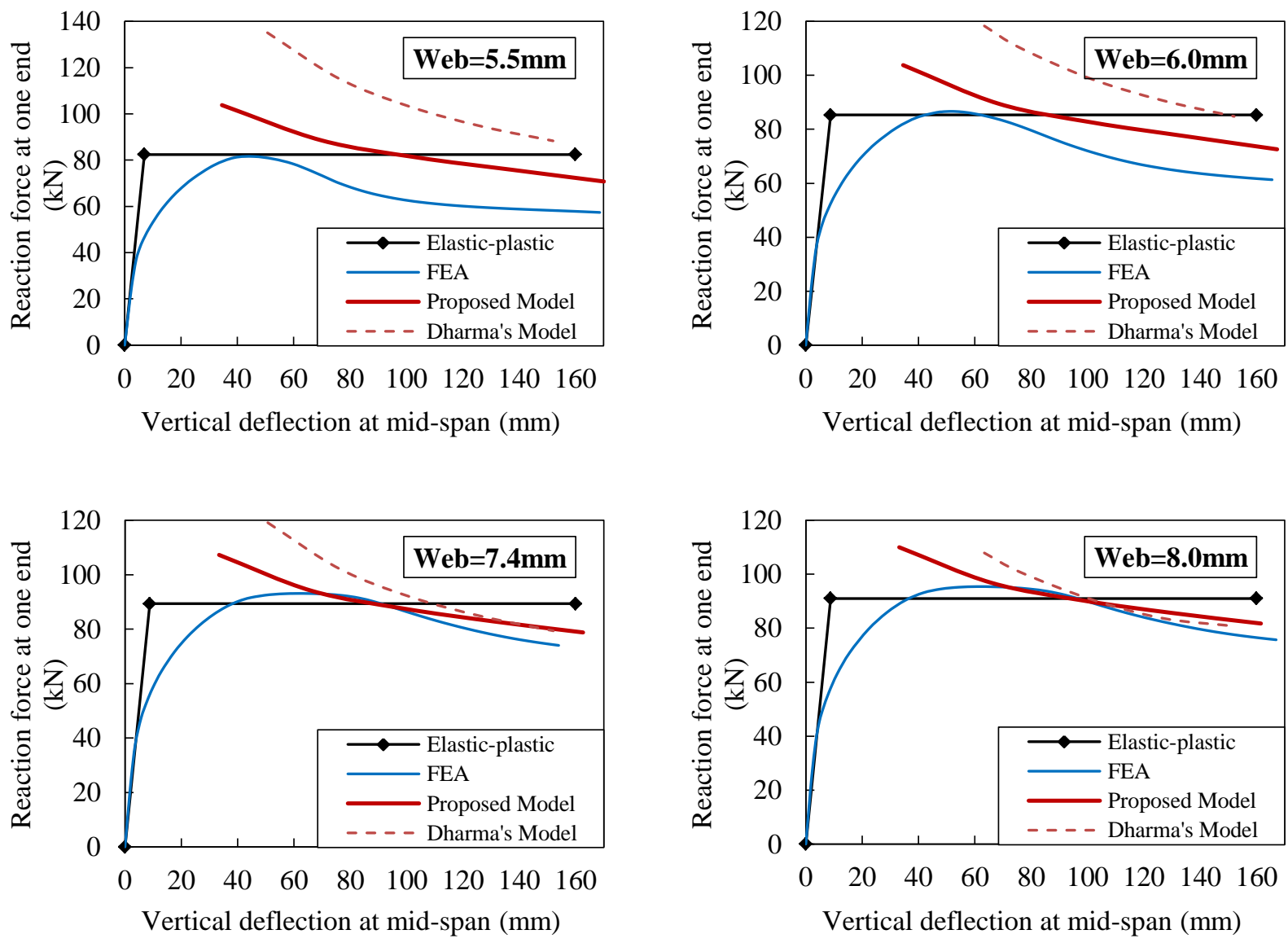

FIGURE 8. Comparison between the analytical model, Dharma's model and FE analysis (web thickness varies).

\begin{tabular}{ccccc}
\hline$f_{y, \Theta}\left(\mathrm{N} / \mathrm{mm}^{2}\right)$ & $\varepsilon_{y, \Theta}(\%)$ & $\varepsilon_{t, \Theta}(\%)$ & $\varepsilon_{u, \Theta}(\%)$ & $E_{\alpha, \Theta}\left(\mathrm{N} / \mathrm{mm}^{2}\right)$ \\
\hline 224.4 & 2 & 15 & 20 & 201697 \\
\hline
\end{tabular}

TABLE 1. Material properties.

varied between $10 \mathrm{~mm}$ and $13 \mathrm{~mm}$. In the cases validated, the potential beam length was $6 \mathrm{~m}$, on the basis that a beam depth-to-length ratio of $1 / 20$ is commonly used in design practice. The cantilever length was $1267.8 \mathrm{~mm}$, which is identical to the distance from the beam-end to its adjacent contraflexure point. The shear force applied to the beam-end was 1732.2q, which enabled the cantilevers to be in the same loading condition as the corresponding end zones of the $6 \mathrm{~m}$ fixed-ended beams.

The stress-strain relationship of the beam material at $615^{\circ} \mathrm{C}$ was defined according to Eurocode 3 [11] - The details of the material properties used in the ABAQUS models are shown in Table 1

\subsection{Comparisons BetWeEn the ANALYTICAL MODEL, DHARMA'S MODEL AND FEA}

The force-displacement relationships given by the proposed analytical model, Dharma's model and the
ABAQUS analyses have been compared. The first group of beams compared have the same flange thickness of $11.5 \mathrm{~mm}$, while their web thickness varies. The detailed curves are shown in Fig. 8. The lines with diamond markers, denoted "Elastic-plastic", represent the force-deflection relationships when the full plastic moment resistance is reached at the middle of the flange buckling zone. The smooth lines without markers represent the results of finite element modelling. The descending solid and dashed lines are the results from the new proposed buckling model and Dharma's model respectively. It can be seen that both the proposed analytical model and Dharma's model give very good comparisons to the FE modelling for beams with thicker webs. The proposed model is able to provide acceptable results for beams with webs within the Class 3 range. However, Dharma's model tends to over-estimate the beam capacity considerably for those with more slender webs.

Fig. 9 shows the second group of comparisons, for 


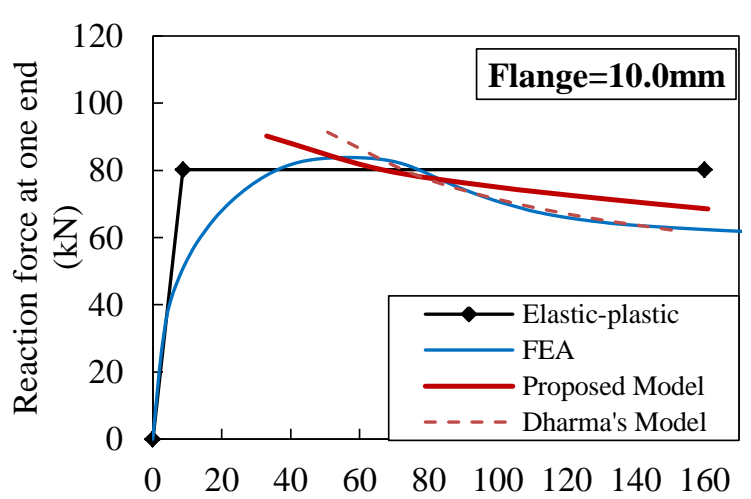

Vertical deflection at mid-span (mm)

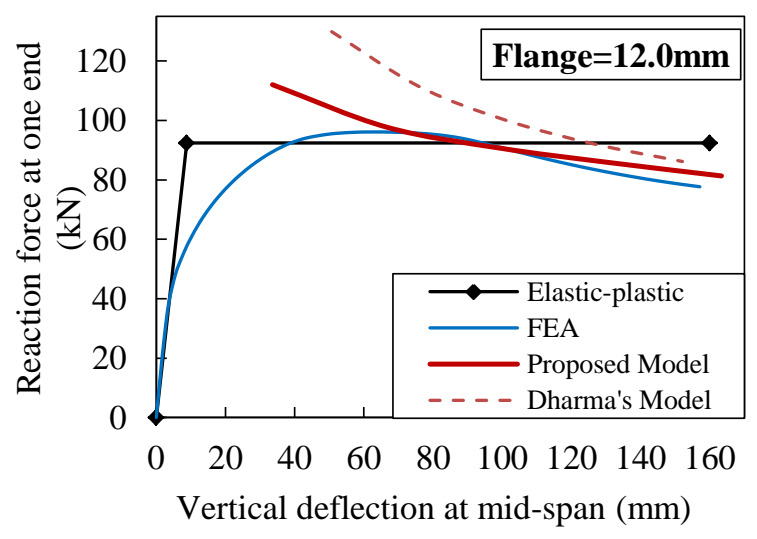

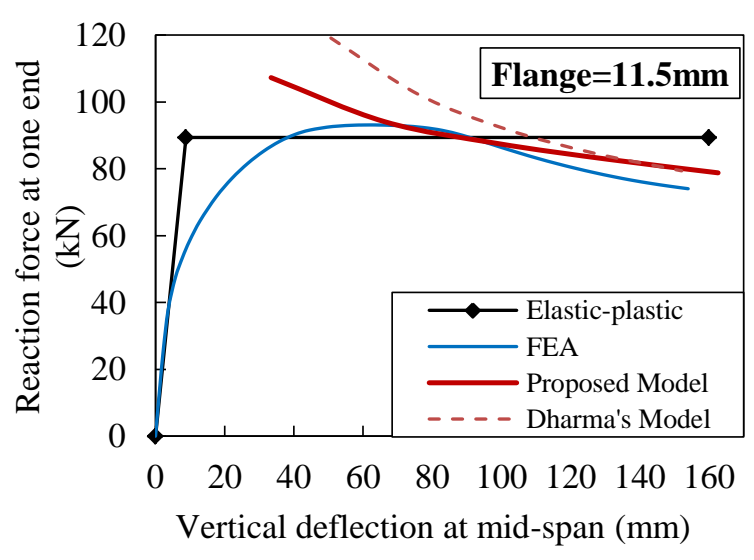

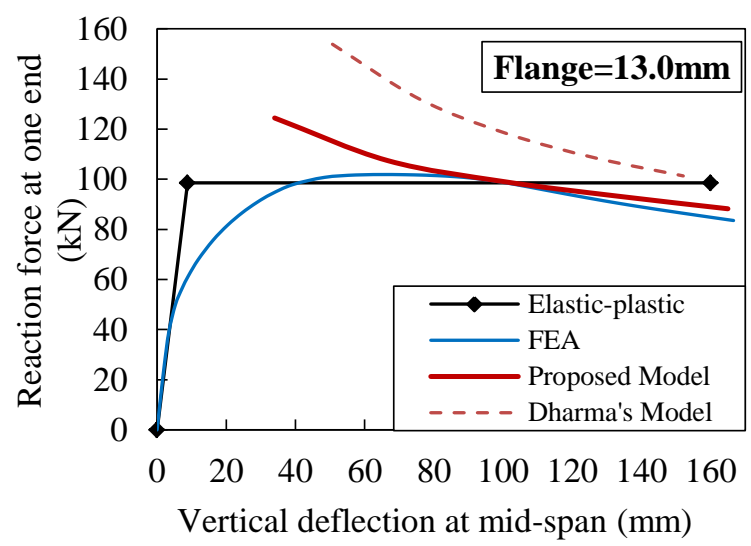

Figure 9. Comparison between the proposed analytical model and Dharma's model (flange thickness varies).

which the beam web thickness remains at $7.4 \mathrm{~mm}$, and the flange thickness varies between $10.0 \mathrm{~mm}$ and $13.0 \mathrm{~mm}$ to guarantee that the beam classification lies in the Class 1 to 2 range. It can be seen that the proposed analytical model compares well with beams within all the selected flange thicknesses, while Dharma's model over-estimates the capacity for beams with stocky flanges. This is possibly because the length of the buckling zone is related to the ratio between $t_{f}$ and $t_{w}$ according to Eq. (1). Decreasing the web thickness or increasing the flange thickness can both increase this ratio. Dharma's model seems more sensitive to the flange-to-web thickness ratio, and therefore considerably over-estimates the capacity when this ratio increases.

The bottom-flange buckling component, representing the beam-end buckling element, is a compressive spring. Its characteristic relies on the flange buckling behaviour, which is related to $\Theta_{1}$ (Fig. 6). The effect of the displacement of the top and bottom springs is effectively a rotation around the top point, connected to the connection element. The characteristic of the shear-buckling component is related to $\Theta_{2}$. The effect of shear buckling is a transverse drift of the two opposite edges of the buckling panel. The length of the buckling component has been defined as identical to the beam depth $(d)$. One of the major objectives of this research is to develop new components representing beam-web shear buckling and flange-buckling, and to implement these together with the adjacent joint element, as shown in Fig. 10, to carry out performancebased frame analysis under fire conditions.

\section{Conclusions}

This paper has briefly reviewed an analytical model proposed to predict the post-buckling behaviour of the end-zones of steel beams at elevated temperatures. The load resistance of a steel shear panel at elevated temperatures involves three stages: Non-linear prebuckling, Plateau and Post-buckling. A whole forcedeflection relationship has been postulated, from initial loading to the post-buckling stage. A range of finite element models has been created using the finite element software ABAQUS. The loading of the cantilever models was uniformly distributed on the top flange, together with a shear force at the beam end. The proposed analytical model was compared with Dharma's existing model and FE models. The comparisons were carried out for beams with different web and flange thicknesses within the Class 1 and 2 range according to the classification method provided by Eurocode 3 [11]. The comparisons showed that the proposed method provides a stable upper bound in terms of the reaction force-deflection relationship 

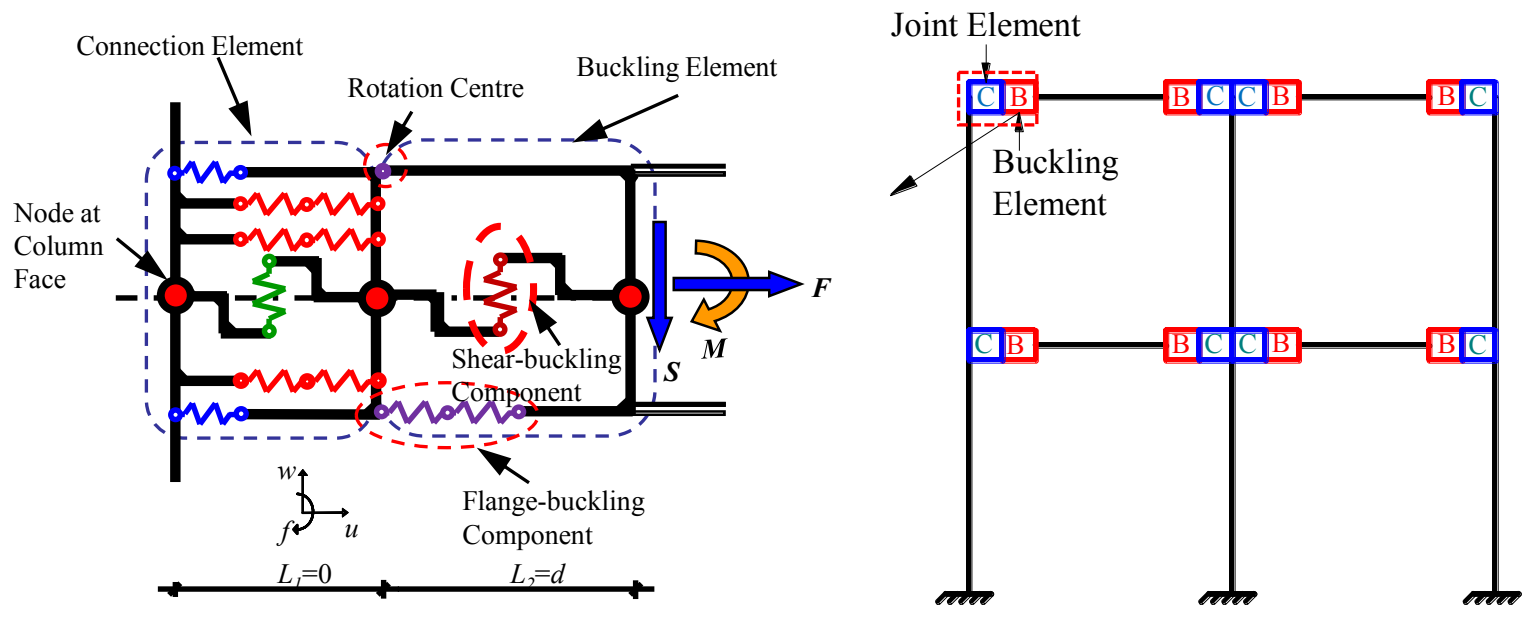

FiguRE 10. Component-based model for buckling components.

within this range, while Dharma's model tends to overestimate post-buckling capacity, especially when the beam flange-to-web thickness ratio is relatively large. Component-based models of the beam-web shear buckling and the bottom flange buckling have been created. The newly developed components will be implemented, in conjunction with the adjacent component-based joint element, to carry out performance-based analysis of steel and composite framed structures under fire conditions.

\section{REFERENCES}

[1] Kirby B. The Behaviour of a Multi-Storey Steel Framed Building Subject to Fire Attack-Experimental Data; British Steel Swinden Technology Centre, United Kingdom. 1998.

[2] Huang Z, Burgess I, Plank R, Reissner M. Three-Dimensional Modelling of Two Full-Scale, Fire Tests on a Composite Building. Proceedings of The Ice-Structures and Buildings. 1999;134:243-55. http://dx.doi.org/10.1680/istbu.1999.31567

[3] Wald F, da Silva LS, Moore D, Lennon T, Chladna M, Santiago A et al. Experimental behaviour of a steel structure under natural fire. Fire Safety Journal. 2006;41:509-22.

http://dx.doi.org/10.1016/j.firesaf.2006.05.006
[4] Newman GM, Robinson JT, Bailey CG. Fire safe design: A new approach to multi-storey steel-framed buildings: Steel Construction Institute; 2000.

[5] Bijlaard FSK. Connections in Steel Structures V: Behaviour, Strength \& Design ; Proceedings of the Fifth International Workshop. Zoetermeer: Bouwen met Staal; 2005.

[6] Elghazouli A, Izzuddin B. Significance of local buckling for steel frames under fire conditions. 4th International Conference on Steel and Aluminium Structures (ICSAS 99): ELSEVIER SCIENCE BV; 1999. p. 727-34. http: //dx.doi.org/10.1016/b978-008043014-0/50187-6

[7] Timoshenko SP, Gere JM. Theory of elastic stability. 1961. McGraw-Hill, New York; 1961.

[8] Quan G, Huang S-S, Burgess I. Component-based model of buckling panels of steel beams at elevated temperatures. Journal of Constructional Steel Research. 2016;118:91-104.

http://dx.doi.org/10.1016/j.jcsr.2015.10.024

[9] Dharma RB. Buckling behaviour of steel and composite beams at elevated temperatures 2007.

[10] Hibbit D, Karlsson B, Sorenson P. ABAQUS reference manual 6.7. Pawtucket: ABAQUS Inc; 2005.

[11] CEN. BS EN 1993-1-2. Design of steel structures. Part 1.2: General rules - Structural fire design. UK: British Standards Institution; 2005. 